\title{
Effect of Post Retirement Occupation on Survival of Academic Staff Retirees: A Case Study of University Of Ibadan, Nigeria
}

\author{
${ }^{1}$ Ajayi, Moses Adedapo, ${ }^{2}$ Shangodoyin Dahud Kehinde, ${ }^{3}$ Mokgathle Lucky and \\ ${ }^{4}$ Thaga, K \\ ${ }^{1,2,3,4}$ Department of Statistics, University of Botswana, Botswana
}

\begin{abstract}
A few years ago, teachers were being encouraged to take early retirement the data was made public concerning the reduction in life expectancy for those who worked longer. The Government now increased the retirement age of academic professorial cadre in Nigeria to 70 years (Olalekan, 2012). I do not believe that it has escaped consideration that extending working life will reduce life expectancy, thus not only raising the age when teachers begin to take their pension, but also reducing the age at which they are no longer there to receive it. In this study, a preliminary survey was made to determine the effect of post retirement occupation on survival of academic staff retirees of University of Ibadan in Nigeria, a follow up study of a cohort of academic retirees in retrospective in a well based record assessment. From total population of 302 of pensionable 60 to 65 years of age of service and 35 years in service as at year 2012 of retired academic staff retirees surveyed, 109 were randomly selected during the study dates "January 1977 to December 2012". Simple descriptive frequency and the Life Table analysis were identified as the most suitable approach to analyze the demographic characteristics and pattern of survival; this provides estimates of probabilities of surviving a given number of years after retirement. Since life table is non-parametric procedure for estimating life expectancy at different points and does not produce a measure of precision. We utilised the distribution of the survival and hazard function to give a more elegant and measure precision of life expectancy. The survival probability shows that there is significant different between PRO of interest and survival time of academic retirees using Log rank (Mantel-cox) test with $p$ value is 0.013 and coefficient of regression analysis $\beta=0.429$ with $p$ value of 0.008 . We can also claim that there is no significant different between post retirement occupation (PRO) of interest and longevity of male and female after retirement age. The survival probability curves and the ANOVA with $p$ value of 0.879 supported the outcome. The survival probability curves for the gender and there duration of service indicates that there is no significant difference in the survival probability with probability of 0.738 .
\end{abstract}

Keywords: Longevity; Retirement; Age; Duration; Expectancy; Service

\section{Introduction}

There is a great deal of interest, world-wide on retirement and old age issues. Many issues are dealt with from different perceptions. While governments are primarily concerned with policies relating to retirement age and pensions, financial ventures focus on the establishment and management of private pension funds and financial securities. From the perception of education, retirement issues moved from relative darkness in 1955 to level of academic discipline in many developed countries in the 80s (Adio-Moses, 2011), Education for and about retirement and old age has since become so vibrant that institution, which specifically target at philosophical, social and economic issues started evolving (Samson 2006).

In a simple form, retirement could be viewed as the process of disengagement from one active service. It is the expectation of individuals that once you are engaged in one employment or the others, you have to retire and pass through the transition stages. Nancy (2004), transitional journey which consist of three stages of Moving Out/Letting Go, Moving Through/Searching, and Moving In/Creating a New life, this transition stages end in death. The interesting thing is how long it takes to survive from points of retirement to death. Longevity is the average number of years one will survive and this is not peculiar to one group of retirees and this is influenced by a number of factors. Kondo et.all (1997), Elena (2005), Lars (2011) carried out studies on many aspects of an individual's life that can influence how satisfied one may be in retirement and this will go a long way to determine the longevity.

Longevity estimates in the statistical sense is the number of years of life remaining at a given age of retirement (Sullivan et all 2003). It can be computed for an individual or for classes of people or for separate group such as between the ages of age intervals. In the light of the above, longevity of retired academic senior staff of universities is not different from other life expectancy of human population. The study will look into longevity of the senior academic lecturer of universities from the inception of retirement till the end of his life 
in relation to duration of service before retirement and Post Retirement Occupations (PRO) in University of Ibadan.

\section{Methods and Discussion}

The study dealt with subjects well-being based on record assessment. The target population of the study comprises all retirees from the University of Ibadan, Nigeria from 1977 to 2012. An important characteristic of the population is that the pensioners' either retired has voluntarily between ages 60 and 64 years or mandatory age 65 years in which case, they are elderly and more vulnerable to negative retirement conditions than employees who voluntarily retired earlier without pension. Two stage sampling technique was adopted for the study. At first stage, which is purposive sampling based on the university with long history of establishment in the country and the voluntary age from ages 60 to 64 and mandatory age 65 with pension's condition of retirement of the participants. The second stage is simple random sampling techniques. The required number of academic universities staff retirees sample size for this study was based on Mark (2009), formula which yields a representative sample for epidemiological study. The sampling procedure for the selection of each retiree into the sample size is based on simple random sampling by drawing numbers that represent 109 retirees from a computed generated random numbers between 1 and 302 of total population of academic retirees as at 2012. Simple descriptive statistics of frequency counts and percentage were used to analyse the data obtained on personal chacteristics of the respondents. Kaplan Meier with Regression and Analysis of Variance (ANOVA) models were used to explain survival experience of academic retirees.

\section{Result and Discussion}

The table 1 below shows the distribution of academic retirees by their demographic characteristics in the period of 37 years of the study. It is observed that population of males' respondents was $76.1 \%$, at inception and for quite some time university academic staff was predominantly male. It is observed that $66.1 \%$ of the surveyed respondents have died according to the administrative record and among the respondents that are alive (33.9\%), only $71.4 \%$ of them are married while $28.6 \%$ are widowed. The table shows the distribution of retirees by reasons for their retirement, those who retired based on the policies of retirement which are 35 years of service is $71.6 \%$ and age limit is $28.4 \%$. From table 1 , it is observed that those retired at age 60 is $24.9 \%$. In this case, the respondents might have served 35 years, which is a condition for mandatory retirement. A period of 35 years is long enough to for the respondents to acquire valuable skills and experiences which may be of use to some other employers or themselves. Those who retired at age 65 are $45.9 \%$, thus confirming the demographic projection of a large population of retirees for mandatory age of retirement.

Table 1: Demographic Characteristics Of The Cohort And Sample

$n=109$

\begin{tabular}{|l|l|l|}
\hline VARIABLES & FREQUENCY & PERCENTAGES \\
\hline GENDER & & \\
Males & 83 & 76.1 \\
Females & 26 & 23.9 \\
Total & 109 & 100.0 \\
\hline CURRENT STATUS & & \\
Censor & 37 & 33.9 \\
Fail & 72 & 66.1 \\
Total & 109 & 100.0 \\
\hline MARITAL STATUS & & \\
Married & 25 & 71.4 \\
Widow & 10 & 28.6 \\
Total & 35 & 100 \\
\hline REASONS FOR & & \\
RETIREMENT & 78 & 71.6 \\
Length of service & 31 & 28.4 \\
Age Limit & 109 & 100 \\
Total & & \\
\hline RETIREMENT AGE & & \\
60 & 32 & 29.4 \\
61 & 7 & 6.4 \\
62 & 4 & 3.7 \\
63 & 4 & 3.7 \\
64 & 3 & 2.8 \\
65 & 59 & 45.9 \\
Total & 109 & 100.0 \\
\hline
\end{tabular}

Table 2 below shows frequency distribution of respondents by their level at retirement and age at retirement. The highest proportion of respondents of academic retirees (83.5\%) was at level of professor while 
level of lecturer 1 was $11.9 \%$ of the total respondents. This shows that academic lecturers prefer to get to the pick of academic career as the case of academic professor. From table 4.3, 81.4\% of the professors retired at compulsory retirement age (65 years) while $15.3 \%$ and $3.4 \%$ of academic lecturer 1 and senior lecturer also retired at compulsory retirement age accordingly. Those who retired at early voluntary retirement age among the academic professors were $81.2 \%$, also $9.4 \%$ and $3.1 \%$ were recorded for lecture 1 and other levels of academic retirement level consecutively.

Table 2: showing frequency distribution of respondents by level at retirement and age at retirement.

\begin{tabular}{|c|c|c|c|c|c|c|c|}
\hline \multicolumn{8}{|c|}{$n=109$} \\
\hline & \multirow[b]{2}{*}{ Age at Retirement } & \multicolumn{5}{|c|}{ Rank at Retirement } & \multirow[b]{2}{*}{ Total } \\
\hline & & Prof & Associate Prof & SL & $\mathbf{L I}$ & LII & \\
\hline \multirow[t]{3}{*}{60} & Count & 26 & 1 & 1 & 3 & 1 & 32 \\
\hline & $\begin{array}{c}\% \text { within Age after } \\
\text { Retirement }\end{array}$ & $81.2 \%$ & $3.1 \%$ & $3.1 \%$ & $9.4 \%$ & $3.1 \%$ & $100.0 \%$ \\
\hline & $\begin{array}{c}\% \text { within Level at } \\
\text { Retirement }\end{array}$ & $28.6 \%$ & $100.0 \%$ & $33.3 \%$ & $23.1 \%$ & $100.0 \%$ & $29.4 \%$ \\
\hline \multirow[t]{3}{*}{61} & Count & 6 & $\mathbf{0}$ & $\mathbf{0}$ & 1 & $\mathbf{0}$ & 7 \\
\hline & $\begin{array}{c}\% \text { within Age after } \\
\text { Retirement }\end{array}$ & $85.7 \%$ & $.0 \%$ & $.0 \%$ & $14.3 \%$ & $.0 \%$ & $100.0 \%$ \\
\hline & $\begin{array}{c}\% \text { within Level at } \\
\text { Retirement }\end{array}$ & $6.6 \%$ & $.0 \%$ & $.0 \%$ & $7.7 \%$ & $.0 \%$ & $6.4 \%$ \\
\hline \multirow[t]{3}{*}{62} & Count & 4 & $\mathbf{0}$ & $\mathbf{0}$ & $\mathbf{0}$ & $\mathbf{0}$ & 4 \\
\hline & $\begin{array}{l}\% \text { within Age after } \\
\text { Retirement }\end{array}$ & $100.0 \%$ & $.0 \%$ & $.0 \%$ & $.0 \%$ & $.0 \%$ & $100.0 \%$ \\
\hline & $\begin{array}{c}\% \text { within Level at } \\
\text { Retirement }\end{array}$ & $4.4 \%$ & $.0 \%$ & $.0 \%$ & $.0 \%$ & $.0 \%$ & $3.7 \%$ \\
\hline \multirow[t]{3}{*}{63} & Count & 4 & $\mathbf{0}$ & $\mathbf{0}$ & $\mathbf{0}$ & $\mathbf{0}$ & 4 \\
\hline & $\begin{array}{c}\% \text { within Age after } \\
\text { Retirement }\end{array}$ & $100.0 \%$ & $.0 \%$ & $.0 \%$ & $.0 \%$ & $.0 \%$ & $100.0 \%$ \\
\hline & $\begin{array}{c}\% \text { within Level at } \\
\text { Retirement }\end{array}$ & $4.4 \%$ & $.0 \%$ & $.0 \%$ & $.0 \%$ & $.0 \%$ & $3.7 \%$ \\
\hline \multirow[t]{3}{*}{64} & Count & 3 & $\mathbf{0}$ & $\mathbf{0}$ & $\mathbf{0}$ & $\mathbf{0}$ & 3 \\
\hline & $\begin{array}{c}\% \text { within Age after } \\
\text { Retirement }\end{array}$ & $100.0 \%$ & $.0 \%$ & $.0 \%$ & $.0 \%$ & $.0 \%$ & $100.0 \%$ \\
\hline & $\begin{array}{l}\% \text { within Level at } \\
\text { Retirement }\end{array}$ & $3.3 \%$ & $.0 \%$ & $.0 \%$ & $.0 \%$ & $.0 \%$ & $2.8 \%$ \\
\hline \multirow[t]{3}{*}{65} & Count & 48 & 0 & 2 & 9 & 0 & 59 \\
\hline & $\begin{array}{c}\% \text { within Age after } \\
\text { Retirement }\end{array}$ & $81.4 \%$ & $.0 \%$ & $3.4 \%$ & $15.3 \%$ & $.0 \%$ & $100.0 \%$ \\
\hline & $\begin{array}{c}\% \text { within Level at } \\
\text { Retirement }\end{array}$ & $52.7 \%$ & $.0 \%$ & $66.7 \%$ & $69.2 \%$ & $.0 \%$ & $54.1 \%$ \\
\hline \multirow[t]{3}{*}{ Total } & Count & 91 & 1 & 3 & 13 & 1 & 109 \\
\hline & $\begin{array}{c}\% \text { within Age after } \\
\text { Retirement }\end{array}$ & $83.5 \%$ & $.9 \%$ & $2.8 \%$ & $11.9 \%$ & $.9 \%$ & $100.0 \%$ \\
\hline & $\begin{array}{l}\% \text { within Level at } \\
\text { Retirement }\end{array}$ & $100.0 \%$ & $100.0 \%$ & $100.0 \%$ & $100.0 \%$ & $100.0 \%$ & $100.0 \%$ \\
\hline
\end{tabular}

It is observed from table 3 below that $83.5 \%$ of the total respondents surveyed were Professors. And majority of them who were professors retired at age 65 years as noted earlier (table 4.3). This shows that academic lecturers are likely to be satisfied with work environment. The shows that $0.9 \%$ retired as Associate Professors and Lecturer II simultaneously while $2.8 \%$ retired as lecturer I. It is observed that $65.1 \%$ of the respondents were retired as a result of age limit. It is possible that these respondents were not incapacitated by ill health, or they were in good health, and that they would otherwise want to continue working if given opportunity. Those who retired as a result of health status is $10.1 \%$. 
Table 3: showing frequency of respondents by level at retirement and reasons for retirement. $n=109$

\begin{tabular}{|l|c|c|}
\hline VARIABLES & FREQUENCY & PERCENTAGE \\
\hline RETIREMENT RANKS & & \\
Professor & 91 & 83.5 \\
Associate Professor & 1 & 0.9 \\
Senior Lecturer & 3 & 2.8 \\
Lecturer I & 13 & 11.9 \\
Lecturer II & 1 & 0.9 \\
Total & 109 & 100.0 \\
\hline REASONS FOR RETIREMENT & & \\
& & \\
Age limit & 71 & 65.1 \\
Length of service & 7 & 6.4 \\
Voluntary & 20 & 18.3 \\
Heath Status & 11 & 10.1 \\
Total & 109 & 100.0 \\
\hline
\end{tabular}

Table 4 shows frequency of respondents by post retirement occupations, performance of post retirement occupations and age the respondents' collected last benefit. It is observed that $85.7 \%$ of the total respondents surveyed involved in academic service after disengagement from academic university service. This support that if there is no limit in academic service majority of the respondents will continue till when they were tired. Few proportions of the respondents, $8.6 \%$ and $5.7 \%$ engaged in community/Public service and small scale business respectively. More so, it was observed that $85.7 \%$ of the respondents surveyed were averagely performing well in their post retirement occupations, $5.7 \%$ of the respondents performed below the average from their respective post retirement occupations. The year that has the highest respondents' claim is 2012 with $33.9 \%$ and least is 2001 with $3.7 \%$.

Table 4: showing frequency of respondents by post retirement occupations, performance of post retirement occupations and age collected last benefit.

$n=109$

\begin{tabular}{|l|c|c|}
\hline VARIABLES & FREQUENCY & PERCENTAGE \\
\hline POST RETIREMENT OCCUPATION & 30 & \\
Educational Consult & 3 & 85.7 \\
Public Service & 2 & 8.6 \\
Small Scale Business & 35 & 5.7 \\
Total & & 100.0 \\
\hline PERFORMANCE IN POST & & \\
RETIREMENT OCCUPATION & 3 & 8.6 \\
Above Average & 30 & 85.7 \\
Average & 2 & 5.7 \\
Below Average & 35 & 100.0 \\
Total & & \\
& & \\
\hline YEARS OF BENEFIT RECEIVED BY & & 5.5 \\
RESPONDENTS & 6 & 3.7 \\
2000 & 4 & 5.5 \\
2001 & 6 & 4.6 \\
2003 & 5 & 4.6 \\
2004 & 5 & 7.3 \\
2005 & 8 & 7.3 \\
2006 & 8 & 8.3 \\
2007 & 9 & 7.3 \\
2008 & 8 & 7.3 \\
2009 & 8 & 4.6 \\
2010 & 5 & 33.9 \\
2011 & 37 & 100.0 \\
2012 & 109 & \\
Total & & \\
\hline
\end{tabular}

Figure 1 below shows the distribution of new academic retirees for each year in the 35 years study period. All academic retirees (109 respondents) were represented. It shows that at later of the surveyed years, the annual number of retirees was much lower than in the early years, whereas it was as much higher at middle years of the study than the later and early years of the study periods. This may be as a result of younger's ages that are joining the academic service. From the table 4.6 (see Appendix), those who retired in the year 2003 and 2004 were $11 \%$ of the respondents respectively in the surveyed years. From the table 4.6, it was shown that year 2000, 2001, 2003 and 2005 had 8.3\% of retirees accordingly. Also year 1989, 1999 and 2005 had 3.7\% of the 
respondents in order during the study period. From table 4.6, age 65 had $54.1 \%$ respondents throughout the surveyed years, age 60 had $29.4 \%$ respondents of the surveyed years while ages 62 and 63 had $3.7 \%$ of the respondents respectively. Those survived till end of the study period was $33.9 \%$ (table 4.2) of the sampled respondents.

. Figure 1: showing distribution of academic retirees by retirement year

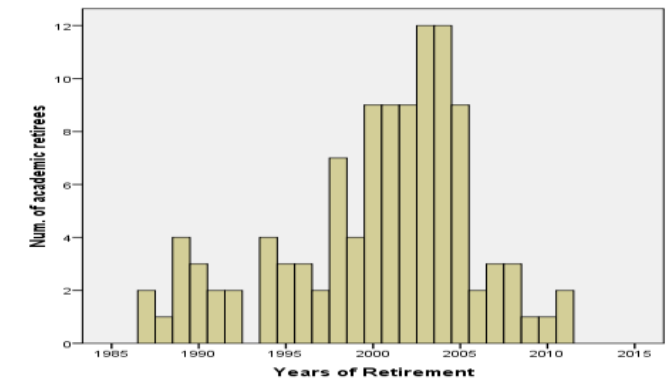

Life expectancy was estimated using survival analysis procedure in SPSS (Kaplan-Meier and life table) for the cohort.

The survival probability curves for the Post Retirement Occupation (PRO) and the survival time of academic retirees are shown in figure 2. The survival probability shows that there is significant different between PRO of interest and survival time of academic retirees using Log rank (Mantel-cox) test with p value is 0.013 .

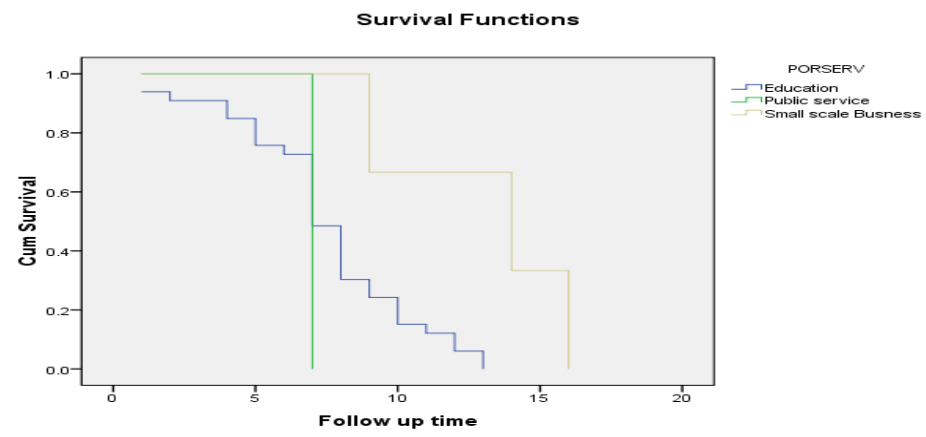

Figure 2: Showing Post Retirement Occupation (PRO) and the survival time of academic retirees

Statistical multiple regressions analysis shows the outcome of the hypothesis that the higher the Post Retirement Occupation (PRO), the longer will be the survival time of academic retirees. The coefficient of regression analysis below show that PRO has significant effect on longevity of academic retirees with $\beta=0.429$ with $\mathrm{p}$ value of 0.01 .

The survival probability curves for the Post Retirement Occupation (PRO) and longevity of gender after retirement age is shown in figure 3 below. The survival probability shows that there is significant different between PRO of interest and longevity of male and female after retirement age and even female are more involve in educational consult than male after retirement.
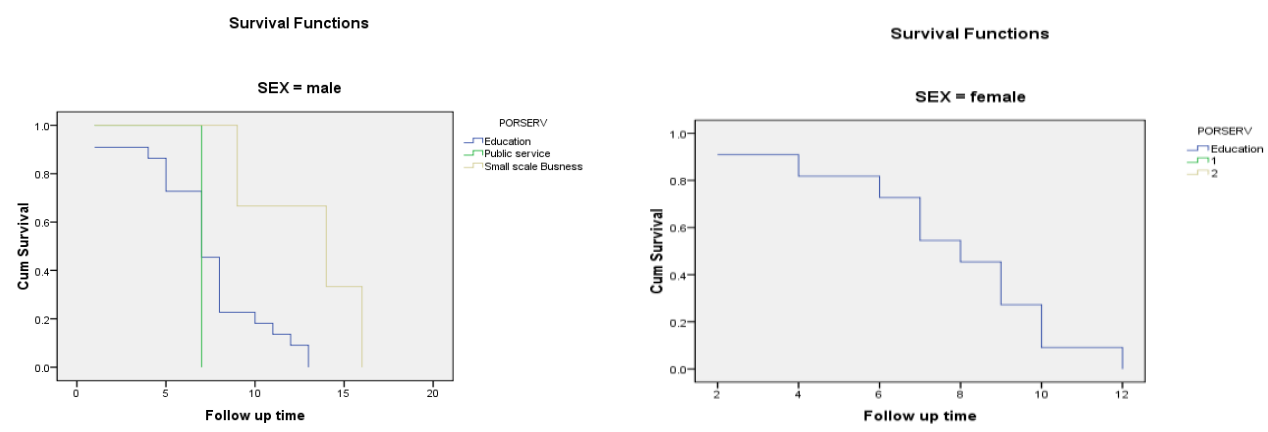

Figure 3: Survival distribution of Post Retirement Occupations (PRO) and longevity of gender after retirement age. 
The hypothesis that there is no difference between Post Retirement Occupations (PRO) and longevity of gender after retirement age was tested using Analysis of Variance (ANOVA) was shown in table 4.9 below. It is observed that there is significant difference between PRO and longevity of gender of academic retirees with the $\mathrm{p}$ value of 0.409

Figure 4 shows the survival distribution by gender and their duration of service during the study period. The survival probability curves for the gender and there duration of service is shown in figure 4.5. There were no significant differences in the survival probability for the two groups. Estimation using Log rank (Mantel-cox) test with $\mathrm{p}=0.738$, the difference between male and female survival functions was not significant.

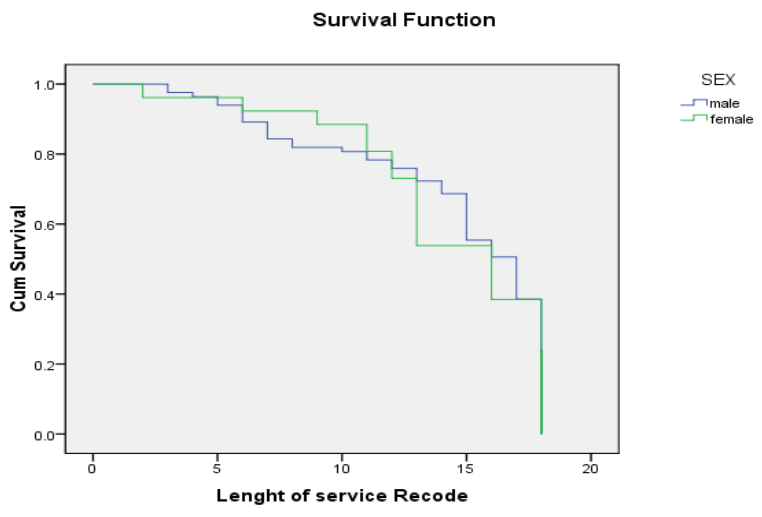

Figure 4: Showing survival distribution of gender by duration of service before retirement of academic retirees.

The hypothetical analysis that confirms the longevity of gender of academic retirees and their duration of service using Analysis of Variance (ANOVA), the result table 4.12 shows that there is significant different between longevity of gender of academic retirees and their duration of service with $p$ value of analysis of variance that is 0.879 .

\section{Conclusion}

The survival probability (figure 2) shows that there is significant different between PRO of interest and survival time of academic retirees using Log rank (Mantel-cox) test with p value is 0.013 and coefficient of regression analysis with $\beta=0.429$ with $\mathrm{p}$ value of the coefficient of regression 0.008 . The type of post retirement occupation matter most, those who involved in educational consult have higher survival probability than business or public service. These may be as a result past experience with less stress. We can also claim that there is significant different between PRO of interest and longevity of male and female after retirement age and even female are more involve in educational consult than male after retirement. The survival probability curves and the ANOVA with $\mathrm{p}$ value of 0.879 supported the outcome. The survival probability curves for the gender and there duration of service as shown in figure 4 indicates that there is no significant difference in the survival probability for the two Groups. Estimation using Log rank (Mantel-cox) test with probability of 0.738, the difference between male and female survival functions was not significant. More so, one could infer that duration of service before retirement does not have effect on longevity of retired academic staff of university this was supported by argument put forward by Ujiwal (2011) that the longer you work and the longer you handle work related to stress in your life, the less are your chances of survival after retirement.

\section{References}

[1]. Adio-Moses, A.N (2001): Pre-retirement education and improved welfare of retirees in some selected industries in Lagos State Thesis, Adult Education Department, University of Ibadan

[2]. Elena Armandola, (2005): Time and the Biology of Aging, Medscape General Medicine.

[3]. Kondo K, Iwamoto T, Hirano R. (1997): Factors affecting longevity, Southeast Asian J Trop Med Public Health.

[4]. Lars Wilhelmsen (2011): Lifestyle affects life expectancy more than genetics, Swedish study finds, University of Gothenburg

[5]. Nancy Schlossberg (2004): Retire Smart: Retire Happy, (published by The American Psychological Association, Washington, D.C.

[6]. Olalekan Adetayo (2021): Jonathan signs Profs' retirement age into law, The Punch - Nigeria's Most Widely Read Newspaper.

[7]. Samson Omo Aikhoje (2006): Influence of Personal and Psycho-Social Factors on Satisfaction with Retirement life of Retirees from Selected Federal Universities in Southern Nigeria. Thesis, Adult Education Department, University of Ibadan.

[8]. Sullivan, Arthur; Steven M. Sheffrin (2003): Economics: Principles in action. Upper Saddle River, New Jersey 07458: Pearson Prentice Hall.

[9]. Ujwal Deshmukh (2011): Retirement Age and Life Expectancy, www.PenangMyHome.com 